\title{
Policy analysis: Palliative care in Ireland ${ }^{\text {is }}$
}

\author{
Peter May $^{\mathrm{a}, *}$, Geralyn Hynes ${ }^{\mathrm{a}}$, Philip McCallion ${ }^{\mathrm{a}, \mathrm{b}}$, Sheila Payne ${ }^{\mathrm{a}, \mathrm{c}}$, \\ Philip Larkin ${ }^{\mathrm{d}}$, Mary McCarron ${ }^{\mathrm{a}}$ \\ a School of Nursing and Midwifery, Trinity College Dublin, D'Olier Street, Dublin 2, Ireland \\ b School of Social Welfare, University at Albany, State University of New York, 1400 Washington Avenue, Albany, NY 12222, United States \\ ${ }^{c}$ International Observatory on End of Life Care, Division of Health Research, Faculty of Health and Medicine, Boland Tower South, \\ Lancaster University, Lancaster LA1 4YT, United Kingdom \\ d School of Nursing, Midwifery and Health Systems, UCD Health Sciences Centre, University College Dublin, Belfield, Dublin 4, Ireland
}

\section{A R T I C L E I N F O}

\section{Article history:}

Received 20 March 2013

Received in revised form 12 July 2013

Accepted 16 July 2013

\section{Keywords:}

Palliative care

Terminal care

Hospices

Policy making

Health policy

Ireland

\begin{abstract}
A B S T R A C T
Palliative care for patients with advanced illness is a subject of growing importance in health services, policy and research. In 2001 Ireland became one of the first nations to publish a dedicated national palliative care policy. This paper uses the 'policy analysis triangle' as a framework to examine what the policy entailed, where the key ideas originated, why the policy process was activated, who were the key actors, and what were the main consequences. Although palliative care provision expanded following publication, priorities that were unaddressed or not fully embraced on the national policy agenda are identified. The factors underlying areas of non-fulfilment of policy are then discussed. In particular, the analysis highlights that policy initiatives in a relatively new field of healthcare face a trade-off between ambition and feasibility. Key policy goals could not be realised given the large resource commitments required; the competition for resources from other, better-established healthcare sectors; and challenges in expanding workforce and capacity. Additionally, the inherently cross-sectoral nature of palliative care complicated the co-ordination of support for the policy. Policy initiatives in emerging fields such as palliative care should address carefully feasibility and support in their conception and implementation.
\end{abstract}

(c) 2013 Elsevier Ireland Ltd. All rights reserved.

\section{Introduction}

Palliative care is an interdisciplinary specialism that focuses on improving quality of life for patients with advanced illness and their families through pain and symptom management; integrated social, spiritual and psychological support; and appropriate transitions

\footnotetext{
is Declaration: This paper was written as part of a larger research project funded by The Atlantic Philanthropies.

* Corresponding author at: Centre for Health Policy and Management, Trinity College Dublin, 3-4 Foster Place, Dublin 2, Ireland.

Tel.: +353 1896 2201; fax: +35316774956.

E-mail addresses: mayp2@tcd.ie (P. May), hynesge@tcd.ie (G. Hynes), pmccallion@albany.edu (P. McCallion),

s.a.payne@lancaster.ac.uk (S. Payne), philip.larkin@ucd.ie (P. Larkin), mccarrm@tcd.ie (M. McCarron).
}

between care settings and pathways [1,2]. In the context of demographic change and emerging complex needs at end of life, the World Health Organization (WHO) has identified palliative care as an important but neglected public health issue requiring an urgent policy response [3].

In 2001 Ireland became one of the first nations to publish a dedicated national palliative care policy. The report of the National Advisory Committee on Palliative Care (NACPC) identified the number of beds, staff and capital facilities required on a per-capita basis with a view to implementing a comprehensive national service, and its recommendations were accepted as official government policy upon publication [4].

At a time when national and international bodies are formulating and implementing policy on palliative care [5-10], this paper analyses the Irish experience: the origin and substance of national policy content, the 


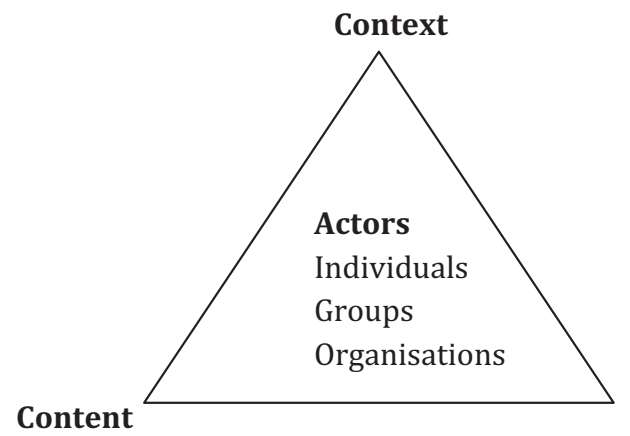

Process

Fig. 1. Policy analysis triangle, Walt and Gilson (1994) [13].

context and actors involved, and the effects on available services.

\section{Methods}

\subsection{Framework}

Best-practice guidance for health policy analysis advocates rooting the research in an existing framework [11] which organise enquiry by identifying elements and relationships between elements [12]. The Walt and Gilson framework [13] takes a political economy perspective on health policy analysis with a 'policy triangle' approach that focuses on content, context, processes and actors (Fig. 1):

- Context refers to systemic factors - political, economic, social; national and international - that may influence health policy;

- Process refers to the way in which policies are initiated, developed, negotiated, implemented and evaluated;

- Content is the substantive detail of the policy encompassing its constituent parts;

- Actors is the short-hand term to denote individuals, organisations and governments who influence policy [14].

The policy triangle framework has been widely applied in many different countries and to a variety of health policy concerns [15]. In this paper it is used as the organising framework for the results of documentary and content analyses.

\subsection{Data collection}

A documentary and content analysis addressed all relevant policy and service documents developed at a national and regional level from 1994 (the date of the first official statement on palliative care policy). Some documents subsequently identified and added by the research team as critical were pre-1994.

Documents to be reviewed were identified and accessed by:

1. Contacting health service administrators and managers.

2 . Visiting libraries in regional offices and education centres.
3. Performing searches of:

- the Lenus database, the Irish Health Repository for all publications produced by the Health Service Executive and related health boards;

- Government websites for reports referring to palliative care, particularly, the Department of Health and Children and Department of An Taoiseach websites;

- Records of parliamentary debates reported on the Oireachtas Debates website.

4. Accessing documents found in the bibliography listings in initially sourced reports.

The roll-out of hospice and palliative care policy also coincided with a major reorganisation of Irish health service administration. Prior to 2005 the country was divided into 10 regional health boards responsible for implementing national policy; in 2005 these were abolished and replaced by a national Health Service Executive (HSE) responsible for implementing policy. While this did not change the content or direction of policy it did alter the regulatory and organisational framework in which policy was implemented.

Keywords searched for were end-of-life, hospice, supportive or palliative care.

Policy documents, annual reports, service plans, needs assessments, parliamentary reports and inspection were sourced through the HSE, Department of Health and Children, Department of An Taoiseach (Prime Minister), the Oireachtas (Irish Parliament) and regional bodies.

A scoping search of journal articles on palliative care in Ireland was also undertaken and relevant findings reviewed. Finally, the document and correspondence databases of relevant statutory and voluntary bodies were searched systematically.

A total of 185 documents were identified and reviewed.

\subsection{Data analysis}

Data analysis involved a directed content analysis approach, which is guided by a structured process or prompts, and incorporated deductive category application [16]. In keeping with the Walt and Gilson framework, analysis was directed by eight headings (Table 1 ).

Two authors, one with a background in palliative care teaching and practice, and another with a background in public policy analysis and design, performed the analysis. Findings were analysed in structured discussions between the wider research team. Where necessary, clarification and additional detail was sought through personal communication with key stakeholders in the statutory and voluntary sectors.

\section{Results}

\subsection{Context}

Palliative care in Ireland has a long history originating in the voluntary sector and services continue to be characterised by strong local voluntary-sector involvement 
Table 1

Headings for data analysis.

\begin{tabular}{|c|c|}
\hline Content focus & Attributes \\
\hline Availability of service & $\begin{array}{l}\text { Volume; quality; access (by age; diagnosis; } \\
\text { service; geographical equity) }\end{array}$ \\
\hline Patient experience & $\begin{array}{l}\text { Voice \& participation; advocacy; } \\
\text { awareness of service availability; } \\
\text { promotion of standards for care }\end{array}$ \\
\hline Policy & $\begin{array}{l}\text { Awareness of policy issues within } \\
\text { government and the public sphere; policy } \\
\text { \& systems level change; Ireland's position } \\
\text { relative to other countries }\end{array}$ \\
\hline Strategy & Strategy statements and challenges \\
\hline Workforce & Number of workers; training \& education \\
\hline Capital & Pre-existing assets \\
\hline Benchmarking & $\begin{array}{l}\text { Assurance \& monitoring; evaluation; } \\
\text { establishment of standards for roll out } \\
\text { nationally }\end{array}$ \\
\hline Research & $\begin{array}{l}\text { Activity; capacity; evidence base on best } \\
\text { practice }\end{array}$ \\
\hline
\end{tabular}

in the planning and delivery of services [17]. This voluntariness encompasses a range of key concepts, including: community, independence, advocacy, not-for-profit and volunteering [18]. Services are therefore typically locallydriven and independently minded.

Local development of services has also led to uneven development, however. In the state's largest three cities centres for the dying were established by religious orders in the late 18th and early 19th century; by 2001 these specialist in-patient hospices were well established community institutions with advanced fundraising networks, strong working relationships with health administrators at regional and national level, and enduring links with the local Roman Catholic Church.

The expansion of services in hospital, hospice and homecare settings beyond these three institutional settings began in the mid-1980s, driven by the modern hospice movement. This movement, voluntary sector-led, adopted the ideas, philosophy and path of the hospice movement in the United Kingdom, where modern hospice originated under the leadership of Cicely Saunders, and ensured some availability of specialist palliative care at home to all areas of the country. Initiated by the Irish Cancer Society, the Irish hospice movement gradually increased access by diagnosis to non-malignant patients over time.

Despite considerable successes for the modern hospice movement, in smaller cities and rural areas there was still variation in the availability of specialist care by 2001. Of Ireland's 10 regional health boards, three were without a specialist in-patient hospice. Among the seven regions that did have a specialist hospice there was large variation in financial support from the local health board. There were seven palliative care consultants in Ireland, but only one of these worked in an area without a hospice, emphasising the geographical inequity. Those regions without a hospice continued to provide palliative care mainly led by generalist doctors.

Alongside the voluntary-driven expansion of services, through the 1990s there was also increased statutory funding available for palliative and end-of-life care, and its profile rose in national policy documents [19,20]. In 1995 Ireland became the second country to recognise palliative care as a medical specialism. Allied to this growing social and political presence of palliative care was the economic growth achieved across Ireland. For over 10 years from 1995 the country experienced unprecedented and almost uninterrupted growth, the so-called 'Celtic Tiger' era.

The publication of the NACPC report and its acceptance as national policy therefore reflected the growing profile and influence of palliative care in social and political spheres in an era of increased healthcare spending. But the competition for new healthcare spending would be fierce, driven by long-standing under-resourcing compared to international trends [21]. From 1980 to 1993 health spending in Ireland dropped by nearly a quarter compared to an equivalent rise in 13 other OECD countries; these cuts led to service cuts and limited bed capacity with a long-standing legacy in the Irish health system [22].

So while palliative care was backed by a new national policy in 2001, it was at the same time the 'new kid on the block' at a point when many established services were competing for resources to restore budget levels to those from the early 1980s.

\subsection{Content}

The policy document mapped out a strategy for the development of comprehensive specialist hospice and palliative care services over a five-year period, identifying the number of beds, staff and capital facilities required on a per-capita basis by region. Universal access irrespective of location and diagnosis, and easy transition between care settings according to clinical situation and preferences, were emphasised (Table 2).

The NACPC provided a full estimate of staffing costs for implementing their recommendations but were unable to estimate capital costs including beds until detailed regional needs assessments had been completed. In 2006 the Irish Hospice Foundation produced a cost estimate of fully implementing the policy recommendations in terms of both beds and staff, setting required annual revenue at $€ 144$ million. Against a national annual spend of $€ 53$ million at this time, this required over $€ 90$ million annually a budget increase of $160 \%$. In addition, capital investment was required to build SIPUs (and, in sparsely populated rural areas, satellite facilities) in underserved areas.

Another significant element of the policy was articulating different levels of palliative care expertise from basic (level one) to specialist (level three). At basic level, palliative care principles were to be practised by all health care professionals with direct patient contact in the belief that the majority of dying patients do not require specialist palliative care intervention but nevertheless require good end-of-life care with symptom management. Level two palliative care involves care from health professionals in general settings who, although not engaged in full-time palliative care, have additional training and experience in palliative care for specific groups and level three is receipt of care from professionals and in settings where core activity is limited to the provision of palliative care.

The principles for organising a universal palliative care service nationally, including the stipulation that each of the 10 health board regions has a SIPU to act as a 
Table 2

Selected recommendations from the Irish national palliative care policy.

\begin{abstract}
- Specialist palliative care services should be available to all patients wherever and whenever they require them on the basis of need, and not on the ability to pay.
\end{abstract}

- Palliative care services should be structured in three levels of ascending specialisation, available in all regional health boards in all care settings.

- All patients should be able to engage easily with the level of expertise most appropriate to their needs, moving from one care setting to another depending on their clinical situation and personal preferences.

- Each health board area should have a comprehensive specialist palliative care service with at least one specialist inpatient unit (SIPU); in areas with a wide geographical spread, it may be necessary to develop a satellite SIPU.

\author{
- The SIPU should be the core \\ essential element of the \\ specialist palliative care \\ service; all other settings, \\ including general hospitals and \\ the community, should be \\ based in or have formal links \\ with the SIPU. \\ - Per-capita bed and staffing \\ requirements were identified; \\ composition of \\ multidisciplinary teams for \\ different settings described - \\ including provision in all acute \\ hospitals. \\ - A menu of further priorities \\ across integral activities \\ including bereavement \\ support, education, training \\ and research, communication, \\ standards, funding and \\ accountability.
}

- There should be a separate protected budget for specialist palliative care services at the health board level. local hub, were the centrepiece of the policy. But the document took a holistic approach, incorporating recommendations across expansion of palliative care principles among generalist and primary care; education, training and research; bereavement support; communication; funding and accountability; planning and development; and implementation.

These recommendations drew on research and policy trends internationally; especially, those emerging in the UK, where modern palliative care originated [23-26]. But the NACPC report itself also called for more research on the best way to organise and deliver services in Ireland, an acknowledgement of the need to grow the evidence base further.

\subsection{Actors}

Palliative care and its policy-led implementation is an inherently cross-sectoral field. The key actors were:

- Central Government: Minister for Health and Children, Taoiseach (Prime Minister), Department of Health and Children civil servants, HSE administrators with responsibility for implementation from 2005 onwards following dissolution of the health boards.

- Local Government: Regional health boards (until 2005), regional administrators, conductors of needs assessments post-2001.

- Healthcare workers: from specialist palliative care, including consultants and nurses; generalists including GPs, hospital medical staff; multidisciplinary support teams, including physiotherapists, pharmacists, speech and language therapists.

- Voluntary and community groups: including the Irish Cancer Society and incorporating many local campaigning groups across the state.

- Educators: typically based in SIPU regional hubs but also including the Irish Hospice Foundation and higher education institutions.

- The Irish Hospice Foundation (IHF): through leading the voluntary and community groups in their work the IHF maintains a strong presence in national policy debates; for example, seeking partnerships with statutory agencies to develop standards of care and extend palliative care provision across difference disease groups.

The make-up of the NACPC itself was three palliative care consultants, three chief executives (one former, two current) and one general manager from the voluntary sector, two representatives from the DoHC and academic centres, one director of public health, one registrar, one public health nurse and one GP.

\subsection{Process}

The NACPC was initiated by the then Minister for Health, Micheál Martin. The committee was chaired by Tony O'Brien, one of seven specialist palliative care consultants in Ireland at this time, and the Government accepted the report in full, adopting it as official policy upon its publication. In adopting in full the NACPC report as official policy, the government had accepted in principle the case for universal palliative care provision on the basis of need.

Initial implementation was slow. Between 2001 and 2004 statutory funding increased $€ 10$ million- $€ 54$ million, some $€ 90$ million short of the NACPC-specified budget and rising at a slower rate than national healthcare spending generally. Moreover, geographical inequity was marked in 2004. The ratio of investment between highest and lowest regions was $20: 1 ; € 30.16$ spent per capita in the North Western region compared to $€ 1.53$ in the Midlands [27].

This slowness was to a large extent explained by the necessary delay while regions performed needs assessments and developed strategies to implement policy, but this work consumed three years of the original five-year timeframe.

The most significant period of service expansion followed between 2004 and 2007. Annual government spending rose from $€ 54$ million to $€ 76$ million, equivalent to $40 \%$ in three years [28], and palliative care availability expanded in all regions of the country. But six years on from the policy publication, and a year past the policy's proposed deadline, spending was still around $50 \%$ of that required.

During this period of spending increases a voluntarysector-led advocacy programme, including 'baseline report' research from the Irish Hospice Foundation (IHF), further highlighted the gap between policy and practice [29]. In particular the IHF highlighted two fundamental shortfalls: the large variation in spending (and so service availability) between regions, and the fact that the three regions without a SIPU in 2001 still remained without one in 2006. 


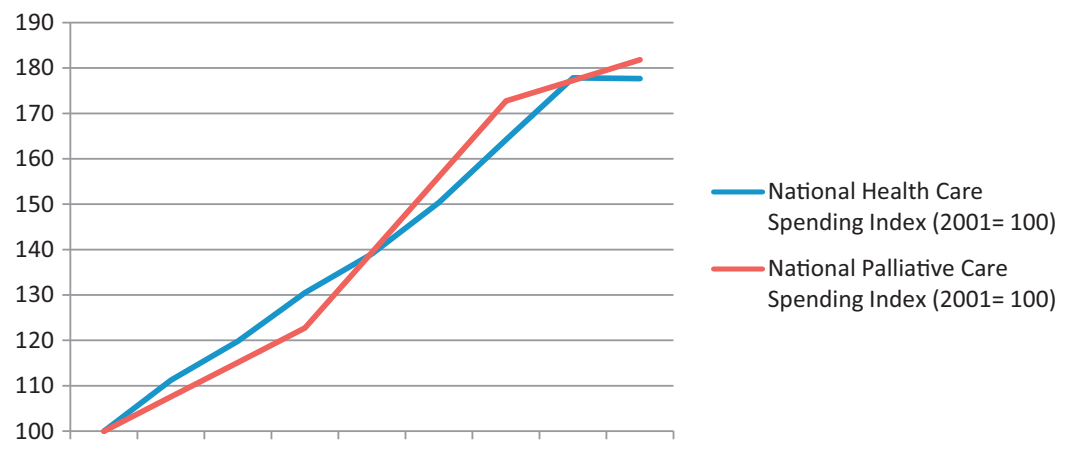

200120022003200420052006200720082009

Fig. 2. Health and palliative care budgets in Ireland (2001-2009).

Faced with concerns that the full realisation of the NACPC vision was not being achieved, Taoiseach (Prime Minister) Bertie Ahern said: 'the baseline study has provided the evidence to underpin the investment and could be viewed as a 'roadmap' of where we want to go and how we want to get there' [30]. And upon Ahern's re-election the following year the 2007 Programme for Government stated, 'We are committed, within the next five years, to removing the regional disparities in the provision and funding of palliative care' [31].

Subsequently the Department for Health and Children initiated an implementation programme detailing 'the required actions and initiatives necessary to address the gaps in palliative care service provision, against the recommendations set out in the NACPC Report' [32]. In particular it structured the development of the remaining capital projects that were required to fulfil national provision.

The renewed political momentum was stymied by external factors. In 2008 Ireland, in common with other high-income countries, entered a severe economic recession. Between 2009 and 2011 annual government expenditure on palliative care dropped back to 2007 levels.

These budget trends were in line with Irish healthcare in general. Fig. 2 indexes the national palliative care spend annually and the national total healthcare spend annually between 2001 and 2009, taking the 2001 level as a baseline at 100 , illustrating that in relative terms both budgets increased along a nearly identical pattern:

By 2011, a decade after the publication of the policy, the national palliative care budget stood at $€ 74$ million [33]. Taking into account inflation, rising costs and increased patient numbers since $\mathrm{a} € 144$ million annual budget need was identified in 2006, this represented less than half that required to fund fully official government policy.

The capital development projects meanwhile were subject to new delays; the regions that had been without a specialist in-patient hospice in 2001 were still without one in 2012. For example, one such underserved region reached advanced stages of planning a new hospice and this was a stated priority in regional and national service plans, but was then excluded from the implemented capital spending plan. This was consistent with persistent geographical inequity more broadly [34].
More recently, emphasis has increased on the need for specialist palliative care services to provide care for patients with non-cancer conditions $[35,36]$. The percentage of non-cancer cases receiving inpatient care increased from $7.2 \%$ in 2004 to $8.5 \%$ in 2011 , and those receiving home care increased from $17 \%$ in 2010 to $20 \%$ in 2011 [35,37].

The policy document's stipulation for development beyond specialist-centred care - expanded generalist capacity, education, training and research; bereavement support; communication; funding and accountability - has also resulted in significant achievements even if some objectives remain outstanding. Irish palliative care services are very well developed by international standards [38].

\subsection{Summary}

Ireland's national palliative care policy had a number of factors in its favour upon publication in 2001. Palliative care in Ireland has a long history and services were among the best developed in the European Union [38]. The policy enjoyed the public support of influential policy actors including the Prime Minister and the health minister. In the eight years following policy publication there was a neardoubling of the national palliative care budget amidst large economic growth. Increased expenditures in the decade following publication did translate into increased levels of hospice and palliative care provision, although they did not produce greater geographic equity and a number of key recommendations remain unaddressed.

\section{Discussion}

The Irish experience with a dedicated national palliative care plan highlights the inherent complexity of health policy implementation and contains lessons for the ongoing development of policy responses in this and other areas.

A first national palliative care plan was published with high-profile political support and a long history of provision on which to build. But with key recommendations unaddressed delays in implementation and curtailment of funding the national policy agenda was not fully achieved.

In her theory of agenda-setting, Hall proposed that an issue gets onto the government agenda only when the issue and its likely response are high in legitimacy, 
feasibility and support [39]. In terms of legitimacy, the national plan was sound. The government had a mandate to provide a national, taxpayer-funded healthcare strategy and palliative care was well-embedded into its communities often with a long history and strong community support. It was in the areas of feasibility and support that problems arose.

The most obvious reason for the failure to fulfil the policy is a shortfall in committed resources. At a fundamental level, full realisation of the NACPC recommendations required significant new investment both in the annual statutory spend on services and staff, and in the development of new capital facilities in underserved areas. In neither case was this investment made fully available. When the global recession started in 2008 the timetable for full policy implementation had already been passed, yet the annual government budget for palliative care was around $50 \%$ of that required to fulfil policy, there had been little capital development and there was no relationship between regional needs and investment [34].

Still, it is worth noting that palliative care was the subject of significant increases: the annual government budget rose $80 \%$ between 2001 and 2009. This is in line with national health spending through the period across the health service at a time when competition for new resources was fierce and urgent. More established areas of the health sector lobbied hard for new investment after years of historic under-funding.

As such, palliative care certainly benefited from the 'Celtic Tiger' years of economic prosperity. But it was not a special case, instead reflective of trends within the healthcare budget more generally.

This was also true in the years following 2009, when the emphasis changed from policy fulfilment to budget protection during a period of sustained health budget cuts. From 2009 to 2012 spending reduced $9.8 \%$ for the health service as a whole and an $8.8 \%$ in palliative care specifically [40,41].

In retrospect, perhaps the magnitude of the actual increase that did occur and the inability to achieve a number of recommendations raises questions about the feasibility of what was proposed. Fulfilment of the NACPC recommendations required a three-fold annual budget increase, plus substantial capital builds, in a five-year period. Given that resources are always scarce, this requirement was both financially and politically demanding, perhaps too demanding.

This question of resource allocation raises a further question about palliative care that those pursuing policy responses must address: the cost-effectiveness of services. Up to a quarter of total healthcare spending is allocated by patients in their last year of life, attributable in part to palliative care, but the evidence base to allocate this funding optimally does not exist [42].

In the Irish context voluntary sector advocacy was successful in raising the profile of palliative care and putting the case for increased investment [29]. But the current economic evidence base for palliative care services is limited, characterised by a small, heterogeneous cost literature and a dearth of cost-effectiveness analysis $[43,44]$. Indeed, the NACPC report itself acknowledged the need for further research on effectiveness and outcome measurement.
The evidence base is growing and there are grounds for cautious optimism, but the practical business of competing for government healthcare resources among many clamouring voices will always be difficult and is increased in economic downturns - more so in the absence of a serious evidence base. The documentary review highlighted that this issue was further complicated by tension between the statutory and voluntary sectors; voluntary-led provision of services appeared characterised by localism and independence, and was not easily complementary to national, top-down data collection and performance management.

In addition to this question of feasibility, a review of all actor perspectives in the Irish palliative care landscape revealed tension in support for the plan as devised and expressed particularly between advocates for specialist care hubs and those who seek more widespread support for application of palliative principles across different care settings. Just $4 \%$ of deaths in Ireland occur in hospices and $25 \%$ at home. The majority of deaths occur in acute (48\%) and residential care services (20\%) [45]. Yet, the NACPC report was written from a strong specialist perspective, advocating specialist-led services nationally in hospices, hospitals and the home. NACPC prioritised specialist palliative care teams within acute care, in the majority of cases patients require basic and intermediate levels of palliative care from non-specialists. A road map for how this was to be achieved was not detailed and addressing the interface between specialist palliative care services and other teams is a problem that is recognised internationally [46].

In 2011 the HSE's national clinical programmes were established to improve and standardise patient care throughout the service [47]. The programmes target different disease groups and services. They included palliative care which aims to ensure that patients with life-limiting conditions and families can easily access a level of palliative care service that is appropriate to their needs regardless of care setting or diagnosis. While the programme builds on the NACPC report, the focus is now on resource utilisation and positioning to support other clinical programmes including chronic diseases. Significantly, the programme is actively seeking to strengthen generalist palliative care. While there is no argument that a specialist-led service is optimal for treating a relatively small number of patients with complex and severe needs, there is now acknowledgement of the simpler needs of a much larger group of patients, and so the training requirements of their carers.

\section{Conclusions}

Palliative care is a major but often neglected public health issue requiring national and international policy responses.

In 2001 Ireland became one of the first countries to publish a dedicated national palliative care policy. This development occurred in the context of a long history of care, a rising profile for provision, political patronage and economic growth. Services expanded following policy publication but the policy struggled to achieve full implementation and key recommendations remain unfulfilled.

As other nations look to develop their own dedicated policy responses to palliative and hospice care concerns, 
the Irish experience emphasises the importance of ensuring priority is given to feasibility and evidence in compiling a plan. Palliative care remains a relatively new field with limited capacity for rapid expansion and challenges in competing for resources with more established areas of a health care system.

Further, this is an inherently complex field crossing the statutory and voluntary sectors and many healthcare disciplines. Careful management by policymakers of different stakeholders across specialist and generalist healthcare workers and public and voluntary sector bodies is vital to ensure support for any national plan, but this is challenging to achieve.

\section{References}

[1] WHO. National cancer control programmes: policies and managerial guidelines, 2nd ed. Geneva: World Health Organization; 2002.

[2] Morrison RS, Meier DE. Clinical practice. Palliative care. New England Journal of Medicine June 2004;350:2582-90.

[3] Davies E, Higginson I. The solid facts: palliative care. Copenhagen: World Health Organization, Regional Office for Europe; 2004.

[4] DoHC. Report of the national advisory council on palliative care. Dublin: Department of Health; 2001

[5] Centeno C, Lynch T, Donea O, Rocafort J, Clark D. EAPC Atlas of Palliative Care in Europe 2013, Full Edition Milan: EAPC Press; 2013.

[6] Hall S, Petkova H, Tsouros AD, Higginson IJ. Palliative care for older people: better practices. Copenhagen: World Health Organization, Regional Office for Europe; 2011.

[7] Department of Health (UK). End of life care strategy: promoting high quality care for all adults at the end of life. DoH (UK), Ed., Crown copyright; 2008.

[8] Ministry of Health. Resource and capability framework for integrated adult palliative care services in New Zealand. Wellington: Ministry of Health; 2013.

[9] Department of Health Ageing. National palliative care strategy 2010: supporting Australians to live well at the end of life. Canberra, Australia: Department of Health and Ageing; 2010.

[10] Escobar Pinzon LC, Munster E, Fischbeck S, Unrath M, Claus M, Martini T, et al. End-of-life care in Germany: study design, methods and first results of the EPACS study (Establishment of Hospice and Palliative Care Services in Germany). BMC Palliative Care 2010;9:16.

[11] Walt G, Shiffman J, Schneider H, Murray SF, Brugha R, Gilson L. 'Doing' health policy analysis: methodological and conceptual reflections and challenges. Health Policy Plan September 2008;23:308-17.

[12] Ostrom E.Institutional rational choice: an assessment of the institutional analysis and development framework. In: Sabatier P, editor. Theories of the policy process, 2nd ed. Boulder, CO: Westview Press; 2007. p. 21-64.

[13] Walt G, Gilson L. Reforming the health sector in developing countries: the central role of policy analysis. Health Policy Plan December 1994;9:353-70.

[14] Buse K, Mays N, Walt G. Making health policy. Maidenhead: Open University Press; 2005.

[15] Gilson L, Raphaely N. The terrain of health policy analysis in low and middle income countries: a review of published literature 1994-2007. Health Policy Plan September 2008;23: 294-307.

[16] Hsieh H-F, Shannon SE. Three approaches to qualitative content analysis. Qualitative Health Research 2005;15:1277-88.

[17] Murphy M, Quinlan P. Managing palliative care services in the Irish Republic. In: Ling J, O’Siorain L, editors. Palliative care in Ireland. Open University Press; 2005.
[18] O’Siorain L, Keegan O, McCormack J. The voluntary sector. In: Ling J, O'Siorain L, editors. Palliative care in Ireland. Open University Press; 2005.

[19] DoH. Shaping a healthier future. Dublin: DoH; 1994.

[20] DoH. Cancer services in Ireland: a national cancer strategy. Dublin: $\mathrm{DoH} ; 1996$

[21] Wren M. "Health spending and the black hole" in unhealthy state: anatomy of a sick society. Dublin: New Island; 2003.

[22] Touche D. Value for money in the Irish health system: main report. Department of Health and Children; 2001.

[23] Saunders C. Care of the dying, etc. (Reprint of articles in the $\backslash 201 C$ Nursing Times. $\backslash 201 D)$. London: Macmillan \& Co.; 1960.

[24] Saunders CMD. The management of terminal disease. London: Edward Arnold; 1978.

[25] Saunders CMD, Summers DH, Teller N. Hospice: the living idea. London: Edward Arnold; 1981.

[26] Available: http://www.cicelysaundersfoundation.org/about-us/ dame-cicely-biography/bibliography (11.03.13).

[27] IHF. "A baseline study on the provision of hospice/specialist palliative care services in Ireland", The Irish Hospice Foundation ISBN 0-9545880-3-9; 2006.

[28] HSE. HSE national service plan. Health Service Executive; 2007.

[29] Murray E. How advocates use health economic data and projections: the Irish experience. Journal of Pain and Symptom Management July 2009;38:97-104

[30] Murray E. Has Ireland's national policy benefited palliative care? European Journal of Palliative Care 2008;15:72-6.

[31] DoT. Programme for government. Dublin: Dot, Taoiseach; 2007.

[32] HSE. Palliative care services - five year/medium term development framework. Dublin: Health Service Executive; 2009.

[33] HSE. HSE national service plan. Health Service Executive; 2011.

[34] May P, Hynes G, McCallion P, Payne S, Higgins A, Larkin P, McCarron $M$. Challenges in increasing regional equity in palliative care service provision in Ireland. EJPC 2013;20(3).

[35] O'Leary N, Tiernan E. Survey of specialist palliative care services for noncancer patients in Ireland and perceived barriers. Palliative Medicine January 2008;22:77-83.

[36] Health Service Executive and Irish Hospice Foundation. Palliative care for all: integrating palliative care into disease management frameworks. Dublin: Irish Hospice Foundation; 2008.

[37] Executive HS. HSE annual report and financial statements 2011. Naas: Health Services Executive; 2012.

[38] Martin-Moreno PJ, Harris M, Gorgojo L, Clark D, Normand C, Centeno C. Palliative care in the European Union. European Parliament; 2008.

[39] Hall P. Change, choice and conflict in social policy. London: Heinemann Educational; 1975.

[40] HSE. HSE national service plan. Cork: HSE; 2009.

[41] HSE. HSE national service plan, HSE: Dublin; 2013.

[42] Haycox A. Optimizing decision making and resource allocation in palliative care. Journal of Pain and Symptom Management July 2009;38:45-53.

[43] Gomes B, Harding R, Foley KM, Higginson IJ. Optimal approaches to the health economics of palliative care: report of an international think tank. Journal of Pain and Symptom Management July 2009;38:4-10.

[44] Smith S, Brick A, O'Hara S, Normand C. Evidence on the cost and cost-effectiveness of palliative care: a systematic review. Palliative Medicine 2013 [Epub ahead of print].

[45] McKeown K, Haase T, Pratschke J, Twomey S, Donovan H, Engling F. Dying in hospital in Ireland: an assessment of the quality of care in the last week of life: national audit of end-of-life care in hospitals in Ireland 2008/9; 2010.

[46] Grande G. Access to palliative care. In: Cohen J, Deliens L, editors. A public health perspective on end of life care. Oxford: OUP Oxford; 2012. p. 86-97.

[47] HSE. National Clinical Programmes. Available: http://www.hse.ie/ eng/services/Find_a_Service/Public_Health/publichealthdepts/ contributetohealthservices/clinprog.html (11.03.13). 